\title{
Toxicity Profile of Commonly Used Anti-Inflammatory Drugs in Geriatrics
}

\author{
Talal M. Ziad Alhouzani ${ }^{\star *}$, Mohammad Saleem ${ }^{1}$, Sitaram Khadka ${ }^{1}$, Saleh Musaed Mohammed Al-Subari ${ }^{1}$, \\ Dhan Bahadur Shrestha², Madiha Rizvi', Imamah Anwar Butt ${ }^{1}$
}

\author{
Author Info: \\ 'Department of \\ Pharmacology, Punjab \\ University College of \\ Pharmacy, University of \\ the Punjab, Lahore-54000, \\ Pakistan \\ ${ }^{2}$ Mangalbare Hospital, \\ Morang, Nepal
}

\section{Corresponding Author:}

Talal M. Ziad Alhouzani

Department of Pharmacology, Punjab University College of Pharmacy, University of the Punjab, Lahore-54000, Pakistan

https://orcid.org/0000-00033801-0442

Email: alhouzanii@gmail.com Contact: 0092-3174304208

\section{ABSTRACT}

Background: Anti-inflammatory drugs are commonly used in geriatrics. Geriatrics usually encounter problems of pain and inflammation and are more vulnerable to the toxicity of drugs as compared to young patients. In this review, we aimed to find out the toxic profile of drugs and the pharmacotherapy considerations for geriatric care.

Methods: The electronic databases like Google Scholar, PubMed, ScienceDirect, and different related text books of recent edition were searched using specific keywords for preparing this narrative review. Related experts in the field were also consulted. Papers published in English language were included in the review.

Results: The diseases geriatrics mostly suffered from are osteoarthritis (OA), ankylosing spondylitis, carcinoma, and other degenerative disorders that require anti-inflammatory medicines. Non-steroidal anti-inflammatory drugs (NSAIDs) and corticosteroids are mostly used agents for the treatment of inflammation in such population. As the pharmacokinetics of drugs get altered due to alteration in body physiology in geriatrics, the pharmacodynamics also gets affected, and hence toxicity ensues even with normal dose. Depending upon the nature of the drugs, presence of comorbidity, and poly-pharmacy; gastrointestinal, renal, and cardiovascular toxicities occur. Due to this reason, utmost care should be taken for pharmacotherapy practice in geriatrics.

Conclusion: In geriatrics, the anti-inflammatory drugs should be used rationally for the shortest duration possible at the lowest effective dose. The careful evaluation of the beneficial and potential risks of the agents and pharmacovigilance must be considered for pharmacotherapy practice in such populations.

Keywords: Anti-inflammatory agents; Comorbidity; Geriatrics; Inflammation

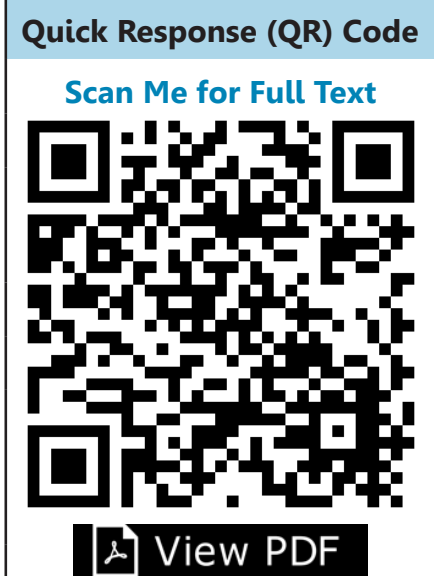

\section{Article Info}

Received: 1 June 2020; Accepted: 28 July 2020; Published Online: 29 July 2020

\section{How to cite this article in Vancouver Style?}

Alhouzani TMZ, Saleem M, Khadka S, Al-Subari SMM, Shrestha DB, Butt IA. Toxicity Profile of Commonly Used Anti-Inflammatory Drugs in Geriatrics. Europasian J Med Sci.2020;2(2): 114-123. https://doi.org/10.46405/ejms.v2i2.107

\section{Conflict of Interest: None Declared;}

\section{Disclaimer}

Source of Support: Nil

Copyright: $(2020$ by author(s). This is an open access article distributed under the terms of the Creative Commons Attribution International License 4.0 (http://creativecommons.org/licenses/ by/4.0/) which permits unrestricted use, distribution, and reproduction in any medium, provided the original work is properly cited.

\section{Publisher's Note}

The Europasian Journal of Medical Sciences (EJMS) (www.europasianjournals.org) is an official Journal of Nirvana Psychosocial Care Center \& Ressearch Institute (www.nirvanapscc.com). The Journal as well as publisher remain neutral with regards to any jurisdictional claims in any published articles, its contents and the institutional affiliations of the authors. 


\section{INTRODUCTION}

The geriatrics mostly face problems of chronic musculoskeletal pain (MSP) as a symptom of different inflammatory diseases like OA especially of knees and hips, gout, ankylosing spondylitis, and other age related degenerative disorders, which are disturbing their quality of everyday life. ${ }^{1}$ The pain may also accompany the different types of carcinomas, diabetes, infections, muscle spasms, ulcers, inflammatory bowel disease (IBD), different neuropsychiatric conditions, and headache in such population. Rheumatoid arthritis (RA), though may occur at any age, may pose a risk of toxicity of the drugs used for intervention thereafter. Among such diseases; pain related to OA, RA, IBD, gout, cancer, ankylosing spondylitis, and other age related degenerative disorders are associated with inflammation. It is crucial to deal with such kind of pain. The pharmacotherapy measure to tackle needs drugs with anti-inflammatory properties which cause toxicity in geriatrics. ${ }^{2}$ Different types of medicines are used to treat pain and inflammation. These are NSAIDs, corticosteroids, disease modifying anti-rheumatic drugs (DMARDs), immunosuppressants, and other supplements like chymotrypsin and serratiopeptidase. Among them, NSAIDs and corticosteroids are mostly used agents around the globe. ${ }^{3}$ Over the counter (OTC) availability of NSAIDs is another reason of maximum use. Therefore, the self-medication practice of such agents has also posed the risk to geriatrics. ${ }^{4}$ This study was carried out with the objectives of finding out commonly used anti-inflammatory drugs, their toxicity profile, pharmacological risks, and to assess pharmacotherapy considerations in geriatrics.

\section{METHODOLOGY}

The electronic databases like Google Scholar, PubMed, Science Direct, and different related text books of recent edition were searched using specific keywords like "anti-inflammatory drugs", "geriatrics", "toxicity profile of anti-inflammatory drugs" and "drug toxicity in elderly" for preparing this narrative review. Related experts in the field were also consulted. Papers published in English language were included in the review.

\section{PHARMACOLOGICAL RISKS IN GERIATRICS}

As geriatrics are vulnerable to toxicity of antiinflammatory drugs, utmost care must be given to these patients. The pharmacokinetic profile of drugs gets altered in geriatrics due to exhaustive physiology as compared to that of adults, which has a direct impact on the pharmacodynamics profile which leads to altered pharmacological effects.5,6 Therefore, age-related changes in physiological and hence pharmacokinetic(PK) and pharmacodynamics(PD) profile as well as comorbidity and poly-pharmacy makes the drug therapy complicated in geriatrics. ${ }^{7,8,9}$

\section{Pharmacokinetic Profile}

Pharmacokinetics may be altered in the elderly due to changes in physiology with age. There is an increase in gastric $\mathrm{pH}$, body fat, or decrease in body mass, gastrointestinal tract (GIT) motility, renal function, serum albumin, phase-I enzymes, and total body water that contribute to the alteration of PK profile. ${ }^{10}$

Absorption There is delayed absorption due to the change in physiology such as delay in gastric emptying, diminished splanchnic blood flow, increased gastric $\mathrm{pH}$, and impairment in intestinal movement. ${ }^{11,12}$

Distribution There is a change in distribution of the drugs as well. Geriatrics have decreased water content, thereby decreasing the volume of distribution (Vd) of water soluble drugs. Similarly, Vd of lipid soluble drugs is increased because of high mass of adipose tissue and less lean muscles. ${ }^{13,14}$

Elimination Due to the decrease in liver mass and perfusion, the hepatic first pass effect of highly cleared drugs through the hepatic route could be reduced in geriatrics, thus some drugs show better bioavailability. The hepatic clearance of some drugs may be reduced by up to $30 \%$ and cytochrome P450 (CYP450) - mediated phase I reactions get impaired more likely than phase II reactions in such population..$^{15,16}$

Renal excretion is decreased up to $50 \%$ in about two thirds of geriatrics, but confounding factors such as hypertension and coronary heart disease account also for depressed renal function. 15,16 Serum creatinine is decreased with age. ${ }^{17}$ Drugs eliminated from the kidney can result in increased concentration and subsequent adverse drug reactions (ADR). All renally eliminated drugs should be monitored carefully. ${ }^{16}$

\section{Pharmacodynamic Profile}

There is a decrease in receptor sensitivity in geriatrics as compared to younger people. ${ }^{13}$ The impact of altered pharmacokinetics may add another burden for disturbing the normal pharmacodynamics profile of drugs. Therefore, the pharmacological effect in geriatrics is more correlated with either 
ineffectiveness or toxicity at a dose which is normal in the adult population. ${ }^{16}$

\section{ANTI-INFLAMMATORY DRUGS COMMONLY USED IN GERIATRICS}

Pharmacotherapy in the management of pain associated with inflammations comprises of drugs of the following categories (Table 1) that modulate or reduce the inflammatory process, thereby decreasing the associated pain. ${ }^{18}$

\section{Anti-Inflammatory Drugs Classification 5,18,19,20}

NSAIDs Diclofenac $\mathrm{Na} / \mathrm{K}$, Naproxyn $\mathrm{Na}$, Indomethacin. Aceclofenac, Aspirin, Ibuprofen, Piroxicam, Mefenamic acid, Celecoxib

Corticosteroids Prednisolone, Methylprednisolone DMARDs Methotrexate, Hydroxychloroquine, Leflunomide, Sulfasalazine, Minocycline, Penicillamine, Auranofin, Etanercept, Infliximab, Adalimumab

\section{Immunosuppressants}

Azathioprine, Mercaptopurine, Cyclosporine, Methotrexate, Hydroxychloroquine

Salicylates Sulfasalazine, Mesalazine

Others Chymotrypsin, Serratiopeptidase

\section{DIFFERENT TOXICITY PROFILE OF ANTI- INFLAMMATORY DRUGS}

Geriatric patients are at more risk to adverse reactions to drugs. Different studies have suggested that ADR observed in patients above age 65 is more as compared to adults. ${ }^{21,22}$

\section{Factors affecting ADRs in geriatrics}

Since poly-pharmacy, multiple disease states, increased severity of illness, reduced drug elimination, and increased sensitivity to drug are associated with geriatrics, these effects make geriatrics more vulnerable to ADRs. ${ }^{14}$

Studies have shown that:

- Patients with numerous medications have a areater chance of experiencina ADRs due to drug-drug interactions and potential overlapping or synergy between adverse reactions ${ }^{8,14}$

- Patients with multiple disease states are at higher risk of having disease-drug interactions $^{23}$

- There are predictions about the possible change in pharmacokinetic and pharmacodynamic profile with age and ADRs observed ${ }^{16}$

- Another issue complicating geriatrics drug therapy includes adherence ${ }^{24}$

- Factors related to gender, socioeconomic status, sedentary life style, poly-pharmacy, complex regimens of drug therapy are also responsible $9,25,26,27,28$

- Other complication, which hinders the disease processes, is also responsible for ADRs $^{29}$

- Improper drug therapy and drug monitoring may add up the ADRs in elderly. ${ }^{30}$

Anti-inflammatory drugs show toxicity in GIT, kidney, cardiovascular system (CVS), and skin, which are depicted in table 2.

\section{NSAIDs}

NSAIDs fall among the mostly prescribed and highly effective anti-inflammatory medications. ${ }^{31}$ However, these have multiple adverse effects such as GIT irritation/hemorrhage, bleeding, CVS side effects, dermatological reactions, and nephrotoxicity. It is very critical to use NSAIDs rationally in geriatrics. ${ }^{32}$

\section{PK \& PD of NSAIDs}

The major therapeutic actions of NSAIDs depend on their ability to block prostaglandins synthesis through cyclooxygenase enzymes (COX-1 and COX-2) inhibition. ${ }^{33}$ COX-1 is expressed in normal cells, while COX-2 is induced in inflammatory cells. COX-2 inhibition represents the desired anti-

\section{Table 1: Anti-inflammatory drugs to treat different geriatric diseases}

\begin{tabular}{|l|l|l|}
\hline SN & Diseases & Anti-inflammatory drugs for treatment \\
\hline $\mathbf{1}$ & OA and other degenerative disorders & NSAIDs, corticosteroids, chymotrypsin or serratiopeptidase \\
\hline $\mathbf{2}$ & IBD & Salicylates, corticosteroids, immunosuppressant \\
\hline $\mathbf{3}$ & Gout & NSAIDs, corticosteroids \\
\hline $\mathbf{4}$ & RA & $\begin{array}{l}\text { NSAIDs, corticosteroids, immunosuppressant, DMARDs, biotechnological } \\
\text { agents }\end{array}$ \\
\hline $\mathbf{5}$ & Cancer & NSAIDs, corticosteroids, immunosuppressant \\
\hline
\end{tabular}


inflammatory response, while COX-1 inhibition plays a major role in the undesired GIT and renal toxicities. ${ }^{19}$

Most NSAIDs are well absorbed in the GIT and have high bioavailability. Some drugs such as diclofenac undergo hepatic first-pass metabolism, while some drugs such as sulindac and parecoxib are prodrugs and need hepatic metabolism to be active. $34,35,36$ NSAIDs are highly bound to plasma proteins and are usually metabolized in the liver, and excreted in the urine. ${ }^{5}$ Common NSAIDs have a variable half-life (0.25-0.3 hours for aspirin or $45-50$ hours for piroxicam). ${ }^{37,38} \mathrm{All}$ these pharmacokinetics parameters can change with aging since the elderly have low body water compared with adults. Protein binding may be reduced and $\mathrm{Vd}$ may be altered. In the case of newer NSAIDs, the most important ADR to be considered is renal damage, which may be irreversible. ${ }^{39}$ Because they are cleared primarily by the kidneys, these drugs will accumulate more rapidly in geriatrics and especially in the patient whose renal function is already compromised. ${ }^{5}$ There is no evidence that COX-2-selective NSAIDs are safer regarding renal function. Geriatrics receiving high doses of any NSAID should be carefully monitored for changes in renal function.

\section{Toxicity Profile}

Renal vasoconstriction and consequently aberrant renal function due to inhibition of prostaglandins and thromboxane synthesis occurs with NSAIDs use. Clinical manifestations of NSAID induced nephrotoxicity include electrolyte imbalance such as hyperkalemia, reduced glomerular filtration rate, chronic kidney disease, acute interstitial nephritis, sodium retention, edema, and renal papillary necrosis. The American geriatric society recommends that all NSAIDs should be avoided in patients with stage IV and V CKD cases (creatinine clearance less than $30 \mathrm{~mL} / \mathrm{min}){ }^{32}$

Gastrointestinal bleeding and ulceration from NSAIDs use an increase in severity and frequency with increasing age. The mechanism underlying NSAIDs induced GIT adverse effects lies in the fact that these medications inhibit prostaglandin synthesis, causing weakening of the protective gastrointestinal mucosal barrier and predisposing to bleeding.

Since rofecoxib and valdecoxib were withdrawn from the market in 2004 and 2005, respectively, due to CVS adverse events such as edema, myocardial infarction, thrombotic events, stroke and hypertension; concerns regarding all COX-2 inhibitors' the potential for CVS adverse events have been raised. ${ }^{40}$ Thus, all NSAIDs (COX-2 and nonselective) may be associated with increased CVS adverse events and each medications' risk/benefit profile should be considered before prescribing to individual patients.

Non-selective NSAIDs are known to attenuate the antihypertensive effect of some specific antihypertensive agents such as angiotensinconverting-enzyme inhibitors (ACEls). The mechanism of NSAIDs promoting hypertension is hypothesized to be related to the inhibition of prostaglandin synthesis, which leads to an interference of the renal vasculature which manipulates the regulation of blood pressure. In addition, NSAIDs themselves can cause elevation of serum aldosterone, leading to sodium retention and hypertension.

As there is evidence of inflammation in alzheimer's brain, there have been different studies regarding the use of NSAIDs in such condition. A study conducted by Grodstein et al revealed that the long-term use of ibuprofen was associated with slower rates of cognitive decline. ${ }^{41}$ Evidences suggest the linkage of elevated pro-inflammatory cytokines to major depression and NSAIDs may play some role in mitigating the anti-inflammatory effects of depression. In adults over 18 years of age, NSAIDs had a statistically significant antidepressant effect in bipolar depression, however, this effect was not seen in geriatrics with depression. Different studies suggest that NSAIDs may play an essential roles in reducing infectioninduced inflammation in this particular scenario. ${ }^{32}$ NSAIDs seem to be a significant risk factor in falls, which can lead to morbidity and mortality in such population. Data from Walker et al suggested that NSAIDs increase the likelihood of falling by 10 fold. NSAIDs are considered an important group of fall risk-increasing drugs (FRIDs). ${ }^{7}$

In animal models, NSAIDs improved bladder function and decreased micturition frequency. Some studies have found significant improvement in the management of nocturia in benign prostatic hyperplasia (BPH) and overactive bladder in geriatrics. ${ }^{32}$ Most probably by altering prostaglandins and prostaglandin precursors in the central nervous system, NSAIDs may get associated with psychiatric events in geriatrics, where the common symptoms may be psychosis, agitation, depression, anxiety, paranoia, delirium, mania, and hallucinations.

NSAIDs not only have analgesics of palliative 


\begin{tabular}{|c|c|c|}
\hline Organ & Toxic reactions & Drugs responsible \\
\hline \multirow{4}{*}{ GIT } & GIT irritation & NSAIDs, salicylates, corticosteroids \\
\hline & GIT hemorrhage/Bleeding & NSAIDs, salicylates, corticosteroids \\
\hline & Ulcer & NSAIDs, salicylates, corticosteroids \\
\hline & Hepatotoxicity & Methotrexate, aspirin, nimesulide \\
\hline \multirow{3}{*}{ Kidney } & Acute renal ischemia & NSAIDs \\
\hline & Acute renal failure & NSAIDs \\
\hline & Acute and chronic interstitial nephritis & NSAIDs \\
\hline CVS & $\begin{array}{l}\text { Edema, myocardial infarction, Thrombotic events, } \\
\text { Stroke and Hypertension }\end{array}$ & NSAIDs, corticosteroids \\
\hline \multirow{4}{*}{ Skin } & Urticaria & Aspirin, NSAIDs \\
\hline & Fixed drug eruptions & Acetylsalicylic acid \\
\hline & Bullous pemphigoid & Sulfasalazine, penicillamine \\
\hline & Angioedema & NSAIDs, corticosteroids \\
\hline
\end{tabular}

action, but also have the potential to lower the risk of cancers such as endometrial, esophageal, head and neck, prostate, colorectal, ovarian cancer and melanoma. As these agents inhibit COX2 expression, which plays a major role in tumor initiation, tumor progression, and suppression of antineoplastic immune cells; these can inhibit cancer cells proliferation and apoptosis induction as a direct effect.

Different studies suggest that NSAIDs can increase the risk of stroke, which varies with type of drugs. Compared with naproxen, the least harmful NSAID for CVS outcomes, valdecoxib was associated with the highest risk of stroke. The incident can occur with the use of valdecoxib, diclofenac, aceclofenac, but no such incidence has been reported with naproxen or ibuprofen. Studies suggest that the long-term use of all NSAIDs can increase the risk of stroke by $64 \%$ in two years. ${ }^{32}$ NSAIDs can interfere with vasoconstriction and sodium excretion causing hypertension, a major risk factor of stroke. These medications can also induce platelet aggregation and increase thrombus formation.

Due to poly-pharmacy ${ }^{9}$, comorbidities $^{23}$, and physiological changes ${ }^{6}$, geriatrics are more vulnerable to drug interactions as depicted in table 3. It is another crucial factor to use NSAIDs and other anti-inflammatory agents with care in geriatrics.

\section{CORTICOSTEROIDS}

Glucocorticoids, as corticosteroids are effective as a clinical milestone for the treatment of numerous inflammatory and autoimmune diseases including bronchial asthma, COPD, allergy, RA, IBD, and multiple sclerosis. However, the therapeutic benefits of corticosteroids are limited by their toxicity profile, especially in high dose or long term use. ${ }^{43}$ Corticosteroids are extremely useful in geriatrics who cannot tolerate full doses of NSAIDs. However, these agents consistently cause doseand duration-related osteoporosis, especially the hazardous toxic effect in the elderly. ${ }^{5}$

\section{PK \& PD of Corticosteroids}

These are administered by oral as well as parenteral route; intravenous, intra-articular, inhalation, and topical route depending upon the clinical status of patients and the urge of action. There is rapid absorption after oral administration with the peak effect occurring at 2-8 hours. It is due to the influence of impaired PK, including that of hepatic, renal function, and concomitant drugs; the alterations in the pharmacological effects of corticosteroids are more apparent in geriatrics.

These agents impede the access of neutrophils and monocytes to an inflammatory site as a major mechanism to exhibit anti-inflammatory effects. ${ }^{44}$ The consideration of impacts of aging on adrenal function is essential for using corticosteroids in geriatrics. For glucocorticoids, the changes of decreased production and decreased clearance are relatively balanced. The reduction in drug dose in such population of asthenic build is appropriate due to the decrease of muscle mass 
Table 3: Interactions of NSAIDs with other agents 5,18,19,20,42

\begin{tabular}{|l|l|}
\hline Medications & Interactions \\
\hline Antiplatelets (aspirin, clopidogrel) & Risk of gastrointestinal bleeding increases \\
\hline $\begin{array}{l}\text { ACEls and Angiotensin receptor } \\
\text { blockers }\end{array}$ & Blood pressure increases due to attenuation of antihypertensive effects \\
\hline Beta blockers & Blood pressure increases by attenuation of antihypertensive effects \\
\hline Calcium antagonists & Blood pressure increases by attenuation of antihypertensive effects \\
\hline Corticosteroids & Risk of gastrointestinal bleeding increases \\
\hline Digitalis glycosides & Serum digoxin level increases \\
\hline Diuretics & NSAIDs reduce renal excretion of methotrexate, causing methotrexate toxicity. \\
\hline Methotrexate & Increases risk of gastrointestinal bleeding \\
\hline $\begin{array}{l}\text { Selective serotonin } \\
\text { inhibitors (SSRIs) }\end{array}$ & Increases risk of gastrointestinal bleeding \\
\hline Warfarin and other anticoagulants & \\
\hline
\end{tabular}

and volume of plasma with aging. Despite the physiologic changes, the careful and ethical use of corticosteroids can be a rational therapy for the optimization of therapeutic outcome in geriatrics. ${ }^{45}$

\section{Toxicity Profile}

Normally, in case of asthma and COPD; geriatrics take corticosteroids through inhalation from a metered dose inhaler or dry powder inhaler. Due to the topical action rather than systemic effects in such cases, these are not that much toxic. Special attention and dose adjustment in geriatrics is needed due to probable age-related changes in hepatic, renal, or cardiac functions. However, steroids like prednisolone, methylprednisolone taken orally can cause the following adverse events $^{46}$ as depicted in table 4, and geriatrics are indeed more vulnerable to these effects.

\section{DMARDs}

These are aqents indicated as standard of care Table 4: ADR profile of corticosteroids 5, 18,19,20

\begin{tabular}{|l|l|}
\hline System & Toxicity profiles \\
\hline GIT & Irritation, dyspepsia, hemorrhage, ulcer \\
\hline Metabolism & Hyperglycemia, cushing's syndrome, weight gain, adrenal suppression \\
\hline CVS & Fluid retention, edema, hypertension, arrythmia \\
\hline Musculoskeletal system & $\begin{array}{l}\text { Osteoporosis, myopathy, osteonecrosis } \\
\text { Dermatology }\end{array}$ \\
\hline Ophthalmology & Glaucoma, cataract \\
\hline Neuropsychiatry & Psychosis, akathisia, sleep disturbances \\
\hline Others & Risk of infection \\
\hline
\end{tabular}

for the therapy of RA where they help prevent joint deformities and injuries. ${ }^{47}$ Basically, DMARDs interfere with the cellular signaling cascade that promotes inflammation. These may also be indicated for the therapy of other autoimmune disorders like scleroderma, spondyloarthritis inflammatory myositis, IBD, and systemic lupus erythematous (SLE) like diseases. Though these have anti-inflammatory activity, these are not the agents mostly being used in geriatrics as RA may occur at any age. However, when it occurs in geriatrics, the condition becomes serious as the toxic profile of drugs may prove dangerous in such patients as compared to adults. By slowing down the joint damage, these agents may induce or maintain remission, reduce the frequency of flareups, and ease steroids tapering with sustained control in disease. DMARDs can be administered orally, subcutaneously, or intravenously. These aqents have delaved onset of action. 
Close monitoring is essential in case of geriatrics taking DMARDs regarding effectiveness and toxicity profile. The toxicity mostly occurs due to the decreased renal clearance of some DMARDs. Therefore, the therapy is to be adjusted according to the clinical status of individuals such as renal function, co-morbidity, concomitant drug administration, or poly-pharmacy. The dose is to be adjusted to the lowest possible level with effectiveness. ${ }^{48}$ The more common toxicities in early therapy is myelosuppression and hepatotoxicity with DMARD. Therefore, more frequent monitoring is recommended early in therapy. ${ }^{49}$ The toxicity of different agents of DMARDs is specific (Table 5).

\section{IMMUNOSUPPRESSANTS}

\begin{tabular}{|l|l|}
\hline Table 5: ADR profile of DMARDs 5,18,19,20 \\
\hline System & Toxicity profiles \\
\hline GIT & Nausea, vomiting, diarrhoea \\
\hline Liver & Hepatotoxicity \\
\hline Blood & $\begin{array}{l}\text { Leukopenia, anemia } \\
\text { Altered QT interval } \\
\text { (Hydroxychloroquine) }\end{array}$ \\
\hline Ophthalmology & $\begin{array}{l}\text { Ocular } \\
\text { (Hydroxychloroquine) }\end{array}$ \\
\hline
\end{tabular}

Immunosuppressants are used in organ transplant cases and auto-immune diseases such as RA, IBD, and cancers. Such type of disease may occur at any age from adults to elderly. These agents may suppress immunity and hence patients may become prone to different diseases. Geriatrics, if use immunosuppressants, may get other diseases very soon due to their altered and weak physiology. ${ }^{50,51}$ So, caution must be given while using such agents to the geriatric population.

In the case of geriatrics, clinically significant alterations in PK parameters occur due to the change is physiology with age. This may lead to higher serum concentration of immunosuppressant. In some cases, such as mycophenolic acid, due to the higher protein binding nature ${ }^{52}$ of the drug and lower albumin level in geriatrics, a higher dose of drug is needed as compared to adults. However, the free fraction of this agent in case of renal insufficiency may cause infections and hematological toxicities..$^{53}$ Geriatrics need appropriate monitoring of therapy of such agents for adherence issues due to the toxicity profile of such drugs. ${ }^{54}$ Immunosuppressants act to prevent allograft rejection by preventing/inhibiting cell activation, cytokine production, differentiation, and/or proliferation..$^{55}$ Appropriate selection of immunosuppressants in geriatrics is complex as such population is considered in exclusion criteria in many studies.

Immunosuppressant may cause myelosuppression leading to anemia, thrombocytopenia, and leukopenia. There are other drug specific adverse events such as methotrexate is also associated with hepatotoxicity, mucosal ulceration, folic acid deficiency, and flu like syndrome. Cyclosporine causes hypertension, nephrotoxicity, hypomagnesaemia, hyperkalemia, hyperlipidemia, and diabetes. Azathioprine causes diarrhea, myelosuppression, pancytopenia, neutropenia, nausea, vomiting, rash, pneumonitis, and liver damage. ${ }^{5,18,19,20}$

\section{OTHERS}

Other anti-inflammatory agents like salicylates, biotechnological drugs, chymotrypsin, and serratiopeptidase also cause ADRs that may prove to be more toxic to geriatrics. Therefore, a detailed clinical picture of patients' needs to be taken and used with caution in geriatrics. They have specific toxicity profile depending upon the agents used. For example, salicylates have a toxicity profile similar to NSAIDs along with bone marrow suppression, nephritis, and hepatotoxicity. 5,18,19,20

\section{GENERAL PRINCIPLES OF PRACTICE IN GERIATRICS}

In the practice of anti-inflammatory agents in geriatrics, care must be taken for the following general principles:

- Start with low dose and reduce slowly ${ }^{56}$

- Due to the reduced renal and hepatic function, the half-life of many drugs will be prolonged in such population ${ }^{14}$

- Rapid dose increase prevents the rapid therapeutic dose response, thereby causing the accumulation of drugs in the body, and ADRs may occur more frequently

- The fewest number of drugs should always be used to treat patients. If possible, emphasize on non-pharmacological measures

- Always evaluate possible drug toxicity

- Geriatrics can have typical presentations of ADRs, which may manifest as CNS changes

- Use other agents along with that counteract the ADR of anti-inflammatory drugs. 
- Practice pharmacovigilance so that identification, monitoring, and management of ADR can be done in an appropriate manner

Different professional societies, including the American geriatric society, American college of rheumatology recommend using NSAIDs with caution and limit their use to the lowest effective dose and shortest duration along with monitoring of gastrointestinal, renal, and cardiovascular side effects. ${ }^{32}$ Gastro-protective agents like proton pump inhibitors, $\mathrm{H}_{2}$ blockers, misoprostol can be used along with anti-inflammatory drugs. ${ }^{3}$ Another strategy to minimize gastrointestinal adverse effects is to substitute nonselective NSAIDs with selective COX-2 inhibitors (celecoxib, rofecoxib) as these agents cause less damage to the gastrointestinal mucosa. However, there are increase risks of cardiovascular adverse effects with COX-2 inhibitors. Thus, a comparison of a patient's gastrointestinal risk factors versus cardiovascular risk factors is necessary to determine the choice of gastrointestinal protection options for patients on chronic NSAIDs. ${ }^{32}$ Osteoporosis can be minimized in corticosteroids users by calcium along with vitamin D or bisphosphonates, and frequent exercise. ${ }^{5}$ The estimates of the total cost of anti-inflammatory agents to the geriatrics must be accompanied by the additional costs of gastro-protective agents and related interventions.

\section{CONCLUSION}

As the body physiology gets exhausted with age; the altered PK and PD profile lead to the different pharmacological effects of drugs in geriatrics that otherwise would have a normal profile in adults. To provide comprehensive care to geriatrics; it is important to consider the mechanism of action, current guidelines, ADRs, and the pleiotropic effects of common drugs. This should be used for the shortest duration possible at the lowest effective dose, and with careful monitoring of gastrointestinal, renal, and cardiovascular toxicity. The benefits of therapy with such agents must be weighed against their potential risks. Alternative therapies such as physiotherapy, psychosocial counseling may also be practiced as far as possible to relieve pain in such populations. The careful monitoring of therapy, pharmacovigilance, comparatively safer agents, topical therapy, or concomitant use of protective agents is recommended for safety concerns in geriatrics.

\section{REFERENCES}

1. Calvani $R$, Marini $F$, Cesari M, Buford TW, Manini TM, Pahor M, Leeuwenburgh C, Bernabei R, Landi F ME. Systemic inflammation, body composition, and physical performance in old communitydwellers. Journal of cachexia, sarcopenia and muscle. 2017;8(1):69-77. https://doi.org/10.1002/ jcsm.12134 [Google Scholar] [PubMed]

2. Solomon DH GJ. Toxicity of nonsteroidal antiinflammatory drugs in the elderly: is advanced age a risk factor? Am J Med. 1997;102(2):208-15. https:// doi.org/10.1016/S0002-9343(96)00380-4 [Google Scholar] [PubMed]

3. Pilotto, A., Sancarlo, D., Addante, F., Scarcelli, C., \& Franceschi M. Non-steroidal anti-inflammatory drug use in the elderly. Surg Oncol. 2010;19(3):16772. $\quad$ https://doi.org/10.1016/j.suronc.2009.11.014 [Google Scholar] [PubMed]

4. Amoako EP, Richardson-Campbell L K-ML. Selfmedication with over-the-counter drugs among elderly adults. J Gerontol Nurs. 2003;29(8):10-5. https://doi.org/10.3928/0098-9134-20030801-05 [Google Scholar] [PubMed]

5. Katzung, B. G., \& Trevor AJ (Eds. ). Basic \& clinical pharmacology. Fourteenth. New York: McGraw-Hill Education.; 2018. [Google Scholar]

6. PP L. Physiological changes due to age. Drugs Aging. 1991;1(5):385-404. https://doi. org/10.2165/00002512-199101050-00006 [Google Scholar] [PubMed]

7. Beers, M.H., Ouslander JG. Risk Factors in Geriatric Drug Prescribing. Drugs. 1989;37:105-112. https:// doi.org/10.2165/00003495-198937010-00008 [Google Scholar] [PubMed]

8. Obreli-Neto PR, Nobili A, de Oliveira Baldoni A, Guidoni CM, de Lyra Júnior DP, Pilger D, Duzanski J, Tettamanti M, Cruciol-Souza JM, Gaeti WP CR. Adverse drug reactions caused by drug-drug interactions in elderly outpatients: a prospective cohort study. Eur J Clin Pharmacol. 2012;68(12):166776. https://doi.org/10.1007/s00228-012-1309-3 [Google Scholar] [PubMed]

9. Nguyen JK, Fouts MM, Kotabe SE LE. Polypharmacy as a risk factor for adverse drug reactions in geriatric nursing home residents. Am J Geriatr Pharmacother. 2006;4(1):36-41. $\quad$ https://doi.org/10.1016/j. amjopharm.2006.03.002 [Google Scholar] [PubMed]

10. Woodhouse KW, Wynne H. The Pharmacokinetics of Non-Steroidal Anti-Inflammatory Drugs in the Elderly. Clin-Pharmacokinet. 2012;12:111-122. https://doi.org/10.2165/00003088-198712020$\underline{00002}$ [Google Scholar] [PubMed]

11. GJ. Y. Altered pharmacokinetics in the elderly. Clin Geriatr Med. 1990;6(2):257-67. [Google Scholar] 
[PubMed]

12. Hilmer SN, McLachlan AJ LCD. Clinical pharmacology in the geriatric patient. Fundam Clin Pharmacol. 2007;21(3):217-30. https://doi.org/10.1111/j.14728206.2007.00473.x [Google Scholar] [PubMed]

13. Tumer N, Scarpace PJ LD. Geriatric pharmacology: basic and clinical considerations. Annu Rev Pharmacol Toxicol. 1992;32(1):271-302. https://doi. org/10.1146/annurev.pa.32.040192.001415 [Google Scholar] [PubMed]

14. Shi S KU. Age-related changes in pharmacokinetics. Curr Drug Metab. 2011;12(7)::601-10. https:// doi.org/10.2174/138920011796504527 [Google Scholar] [PubMed]

15. Klotz U. Pharmacokinetics and drug metabolism in the elderly. Drug Metab Rev. https://doi. org/10.1080/03602530902722679 [Google Scholar] [PubMed]

16. Corsonello A, Pedone C IR. Age-related pharmacokinetic and pharmacodynamic changes and related risk of adverse drug reactions. Curr Med Chem. 2010;17(6):571-84. https://doi. org/10.2174/092986710790416326 [Google Scholar] [PubMed]

17. Fehrman-Ekholm I SL. Renal function in the elderly (> 70 years old) measured by means of iohexol clearance, serum creatinine, serum urea and estimated clearance. Scand J Urol Nephrol. 2004;38(1):73-7. https://doi.org/10.1080/00365590310015750 [Google Scholar] [PubMed]

18. Whalen K. Lippincott Illustrated Reviews: Pharmacology. Seventh ed. Wolters Kluwer; 2019. [Google Scholar]

19. James Ritter Rod Flower Graeme Henderson Yoon Kong Loke David MacEwan Humphrey Rang. Rang \& Dale's Pharmacology. Ninth. ELSEVIER; 2020. [Google Scholar]

20. Goodman LS. Goodman and Gilman's the pharmacological basis of therapeutics. thirteenth. McGraw-Hill; 2018. [Google Scholar]

21. Wu C, Bell CM WW. Incidence and economic burden of adverse drug reactions among elderly patients in Ontario Emergency Departments. Drug Saf. 2012;35(9):769-81. https://doi.org/10.1007/ BF03261973 [Google Scholar] [PubMed]

22. Onder, G., Petrovic, M., Tangiisuran, B., Meinardi, M.C., Markito-Notenboom, W.P., Somers, A., Rajkumar, C., Bernabei, R. and van der Cammen TJ. Development and validation of a score to assess risk of adverse drug reactions among in-hospital patients 65 years or older: the GerontoNet ADR risk score. Arch Intern Med. 2010;170(13):1142-8. https://doi.org/10.1001/ archinternmed.2010.153 [Google Scholar] [PubMed]

23. Davies EA OM. Adverse drug reactions in special populations-the elderly. $\mathrm{Br} \mathrm{J}$ Clin Pharmacol. 80(4):796-807. https://doi.org/10.1111/bcp.12596 [Google Scholar] [PubMed]

24. Hughes CM. Medication Non-Adherence in the Elderly. Drugs Aging. 2004;21:793-811. https://doi. org/10.2165/00002512-200421120-00004 [Google Scholar] [PubMed]

25. Bowman L, Carlstedt BC, Hancock EF BC. Adverse drug reaction (ADR) occurrence and evaluation in elderly inpatients. Pharmacoepidemiol Drug Saf. 1996;5(1):9-18. https://doi.org/10.1002/(SICl)10991557(199601)5:1<9::AID-PDS192>3.0.CO:2-2 [Google Scholar] [PubMed]

26. Sandhiya S AC. Drug therapy in elderly. J Assoc Physicians India. 2008;56:525-31.[PubMed]

27. Boparai MK KB. Prescribing for older adults. Mt Sinai J Med A J Transl Pers Med. 2011;78(4):613-26. https://doi.org/10.1002/msj.20278 [Google Scholar] [PubMed]

28. Stockton $\mathrm{P}$ JJ. Medication use by the elderly. Aging Clin Exp Res. 1993;5(5):337-47. https:// doi.org/10.1007/BF03324184 [Google Scholar] [PubMed]

29. Corsonello A, Pedone C, Corica F, Mussi C, Carbonin $P$, Antonelli Incalzi $R$, et al. Concealed Renal Insufficiency and Adverse Drug Reactions in Elderly Hospitalized Patients. Arch Intern Med [Internet]. 2005;165(7):790-5. $\quad$ https://doi.org/10.1001/ archinte.165.7.790 [Google Scholar] [PubMed]

30. Laroche $M-L$, Charmes J-P, Nouaille $Y$, Picard N, Merle L. Is inappropriate medication use a major cause of adverse drug reactions in the elderly? $\mathrm{Br}$ J Clin Pharmacol. 2007 Feb;63(2):177-86. https:// doi.org/10.1111/j.1365-2125.2006.02831.x [Google Scholar] [PubMed]

31. Phillips, A. C., Polisson, R. P., \& Simon LS. NSAIDs and the elderly. Drugs Aging. 1997;10(2):119-30. https:// doi.org/10.2165/00002512-199710020-00005 [Google Scholar] [PubMed]

32. Wongrakpanich, S., Wongrakpanich, A., Melhado, K., \& Rangaswami J. A comprehensive review of nonsteroidal anti-inflammatory drug use in the elderly. Aging Dis. 2018;9(1):143. https://doi.org/10.14336/ AD.2017.0306 [Google Scholar] [PubMed]

33. Burian M GG. COX-dependent mechanisms involved in the antinociceptive action of NSAIDs at central and peripheral sites. Pharmacol Ther. 2005;107(2):139-54. https://doi.org/10.1016/j.pharmthera.2005.02.004 [Google Scholar] [PubMed]

34. El-Samaligy MS, Yahia SA, Basalious EB. Formulation and evaluation of diclofenac sodium buccoadhesive discs. Int J Pharm. 2004 Nov;286(1-2):27-39. https:// doi.org/10.1016/j.ijpharm.2004.07.033 [Google Scholar] [PubMed]

35. Brunell D, Sagher D, Kesaraju S, Brot N, Weissbach $\mathrm{H}$. Studies on the metabolism and biological activity 
of the epimers of sulindac. Drug Metab Dispos. 2011 Jun;39(6):1014-21. https://doi.org/10.1124/ dmd.110.037663 [Google Scholar] [PubMed]

36. Karim A, Laurent A, Slater ME, Kuss ME, Qian J, Crosby-Sessoms SL, et al. A pharmacokinetic study of intramuscular (i.m.) parecoxib sodium in normal subjects. J Clin Pharmacol. 2001 Oct;41(10):11119. https://doi.org/10.1177/00912700122012607 [Google Scholar] [PubMed]

37. Sher A, Andersen JM, Bhatia SC. Primidoneinduced catatonic schizophrenia. Drug Intell Clin Pharm. 1983;17(7-8):551-2. https://doi. org/10.1177/106002808301700715 [Google Scholar] [PubMed]

38. Hobbs DC, Twomey TM. Piroxicam pharmacokinetics in man: aspirin and antacid interaction studies. J Clin Pharmacol. 1979;19(5-6):270-81. https://doi. org/10.1002/j.1552-4604.1979.tb02480.x [Google Scholar] [PubMed]

39. Bennett WM, Henrich WL, Stoff JS. The renal effects of nonsteroidal anti-inflammatory drugs: summary and recommendations. Am J kidney Dis Off J Natl Kidney Found. 1996 Jul;28(1 Suppl 1):S56-62. https://doi.org/10.1016/S0272-6386(96)90570-3 [Google Scholar] [PubMed]

40. Sun SX, Lee KY, Bertram CT, Goldstein JL. Withdrawal of COX-2 selective inhibitors rofecoxib and valdecoxib: impact on NSAID and gastroprotective drug prescribing and utilization. Curr Med Res Opin. 2007 Aug;23(8):1859-66. https://doi. org/10.1185/030079907X210561 [Google Scholar] [PubMed]

41. Grodstein F, Skarupski KA, Bienias JL, Wilson RS, Bennett DA, Evans DA. Anti-inflammatory agents and cognitive decline in a bi-racial population. Neuroepidemiology. 2008;30(1):45-50. https://doi. org/10.1159/000115749 [Google Scholar] [PubMed]

42. Johnson, AG, Seideman P, Day RO. Adverse Drug Interactions with Nonsteroidal Anti-Inflammatory Drugs (NSAIDs). Drug-Safety. 1993;8:99-127. https://doi.org/10.2165/00002018-199308020$\underline{00002}$ [Google Scholar] [PubMed]

43. Ramamoorthy S, Cidlowski JA. Corticosteroids: mechanisms of action in health and disease. Rheum Dis Clin. 2016;42(1):15-31. https://doi.org/10.1016/j. rdc.2015.08.002 [Google Scholar] [PubMed]

44. Fauci AS, Dale DC, Balow JE. Glucocorticosteroid therapy: mechanisms of action and clinical considerations. Ann Intern Med. 1976;84(3):30415. https://doi.org/10.7326/0003-4819-84-3-304 [Google Scholar] [PubMed]

45. Kaiser FE, Doe RP. Steroid use in the elderly: Guidelines for avoiding adverse effects. Postgrad Med. 1984;76(1):65-74. https://doi.org/10.1080/00 325481.1984.11698664 [Google Scholar] [PubMed]
46. Yasir, M, Sonthalia S. Corticosteroid adverse effects. 2019 [Google Scholar]

47. Brown EM, Garneau KL, Tsao H, Solomon DH. DMARD non-use in low-income, elderly rheumatoid arthritis patients: results of 86 structured interviews. Arthritis Res Ther. 2014 Jan;16(1):R30. https://doi. org/10.1186/ar4459 [Google Scholar] [PubMed]

48. Díaz-Borjón A. Guidelines for the use of conventional and newer disease-modifying antirheumatic drugs in elderly patients with rheumatoid arthritis. Drugs Aging. 2009;26(4):273-93. https://doi. org/10.2165/00002512-200926040-00001 [Google Scholar] [PubMed]

49. Benjamin O, Bansal P, Goyal A et al. Disease Modifying Anti-Rheumatic Drugs (DMARD). StatPearls. 2020 [Google Scholar] [PubMed]

50. Termsarasab $P$, Katirji B. Opportunistic infections in myasthenia gravis treated with mycophenolate mofetil. J Neuroimmunol. 2012 Aug;249(1-2):83-5. https://doi.org/10.1016/j.jneuroim.2012.04.016 [Google Scholar] [PubMed]

51. Naganuma $M$, Kunisaki $R$, Yoshimura N, Takeuchi $Y$, Watanabe M. A prospective analysis of the incidence of and risk factors for opportunistic infections in patients with inflammatory bowel disease. J Gastroenterol. 2013 May;48(5):595-600. https://doi. org/10.1007/s00535-012-0686-9 [Google Scholar] [PubMed]

52. de Winter BCM, van Gelder T, Sombogaard F, Shaw LM, van Hest RM, Mathot RAA. Pharmacokinetic role of protein binding of mycophenolic acid and its glucuronide metabolite in renal transplant recipients. J Pharmacokinet Pharmacodyn. 2009 Dec;36(6):541-64. https://doi.org/10.1007/s10928009-9136-6 [Google Scholar] [PubMed]

53. Atcheson BA, Taylor PJ, Mudge DW, Johnson DW, Hawley CM, Campbell SB, et al. Mycophenolic acid pharmacokinetics and related outcomes early after renal transplant. $\mathrm{Br} J$ Clin Pharmacol. 2005 Mar;59(3):271-80. https://doi.org/10.1111/j.13652125.2004.02235.x [Google Scholar] [PubMed]

54. Ivulich S, Snell G. Long-term management of elderly patients taking immunosuppressive medications. Aust J Gen Pract. 2020;49(3):100. https://doi. org/10.31128/AJGP-10-19-5137 [Google Scholar] [PubMed]

55. Suthanthiran $M$, Morris RE, Strom TB. Immunosuppressants: cellular and molecular mechanisms of action. Am J Kidney Dis. 1996;28(2):159-72. https://doi.org/10.1016/S02726386(96)90297-8 [Google Scholar] [PubMed]

56. McLean AJ LCD. Aging biology and geriatric clinical pharmacology. Pharmacol Rev. 2004;56(2):163-84. https://doi.org/10.1124/pr.56.2.4 [Google Scholar] [PubMed] 